\section{Combining brentuximab vedotin with dexamethasone, high-dose cytarabine and cisplatin as salvage treatment in relapsed or refractory Hodgkin lymphoma: the phase II HOVON/LLPC Transplant BRaVE study}

\author{
Marie José Kersten, ${ }^{1,2^{*}}$ Julia Driessen, ${ }^{1^{*}}$ Josée M. Zijlstra, ${ }^{2,3}$ \\ Wouter J. Plattel, ${ }^{2,4}$ Franck Morschhauser, ${ }^{5}$ Pieternella J. Lugtenburg, ${ }^{2,6}$ \\ Pauline Brice, ${ }^{7}$ Martin Hutchings, ${ }^{8}$ Thomas Gastinne, ${ }^{9}$ Roberto Liu, ${ }^{1}$ \\ Coreline N. Burggraaff, ${ }^{3}$ Marcel Nijland, ${ }^{2,4}$ Sanne H. Tonino, ${ }^{1,2}$ \\ Anne I.J. Arens, ${ }^{10}$ Roelf Valkema, ${ }^{11}$ Harm van Tinteren, ${ }^{12}$ Marta Lopez-Yurda, ${ }^{12}$ \\ Arjan Diepstra, ${ }^{2,13}$ Daphne De Jong $^{2,14}$ and Anton Hagenbeek ${ }^{1,2}$ \\ ${ }^{1}$ Department of Hematology, Amsterdam UMC, University of Amsterdam, LYMMCARE \\ (Lymphoma and Myeloma Center Amsterdam), Cancer Center Amsterdam, Amsterdam, \\ the Netherlands; ${ }^{2} \mathrm{HOVON}$ and Lunenburg Lymphoma Phase I/II Consortium (LLPC), the \\ Netherlands; ${ }^{3}$ Department of Hematology, Amsterdam UMC, Vrije Universiteit \\ Amsterdam, Cancer Center Amsterdam, Amsterdam, the Netherlands; ${ }^{4}$ Department of \\ Hematology, University of Groningen, University Medical Center Groningen, Groningen, \\ the Netherlands; ${ }^{5}$ Department of Hematology, Centre Hospitalier Universitaire, Lille, \\ ${ }^{6}$ Department of Hematology, Erasmus MC Cancer Institute, Erasmus University Medical \\ Center, Rotterdam, the Netherlands; ' Department of Hematology, Hopital Saint Louis, \\ Paris, France; ${ }^{8}$ Department of Hematology, Rigshospitalet, Copenhagen, Denmark; \\ ${ }^{9}$ Department of Hematology, Centre Hospitalier Universitaire, Nantes, France; \\ ${ }^{10}$ Department of Radiology and Nuclear Medicine, Radboud University Medical Center, \\ Nijmegen, the Netherlands; ${ }^{11}$ Department of Radiology and Nuclear Medicine, Erasmus \\ University Medical Center, Rotterdam, the Netherlands; ${ }^{12}$ Department of Biometrics, \\ Netherlands Cancer Institute, Amsterdam, the Netherlands; ${ }^{13}$ Department of Pathology \\ and Medical Biology, University of Groningen, University Medical Center Groningen, \\ Groningen, the Netherlands and ${ }^{14}$ Department of Pathology, Amsterdam UMC, Vrije \\ Universiteit Amsterdam, Cancer Center Amsterdam, Amsterdam, the Netherlands; \\ HOVON Pathology Facility and Biobank, Amsterdam, the Netherlands
}

*MJK and JD contributed equally as co-first authors.

\section{ABSTRACT}

A chieving a metabolic complete response (mCR) before high-dose chemotherapy (HDC) and autologous peripheral blood stem cell transplant (auto-PBSCT) predicts progression-free survival (PFS) in relapsed/refractory classical Hodgkin lymphoma (R/R cHL). We added brentuximab vedotin (BV) to DHAP (dexamethasone, high-dose cytarabine, cisplatin) to improve the $\mathrm{mCR}$ rate. In a phase I dose-escalation part of the study in 12 patients, we showed that BV-DHAP is feasible. This phase II study included $55 \mathrm{R} / \mathrm{R}$ cHL patients (23 primary refractory). Treatment consisted of three 21 -day cycles of BV $1.8 \mathrm{mg} / \mathrm{kg}$ on day 1 , and DHAP (dexamethasone $40 \mathrm{mg}$ days $1-4$, cisplatin $100 \mathrm{mg} / \mathrm{m}^{2}$ day 1 and cytarabine $2 \times 2 \mathrm{~g} / \mathrm{m}^{2}$ day 2). Patients with a metabolic partial response ( $\mathrm{mPR}$ ) or $\mathrm{mCR}$ proceeded to HDC/auto-PBSCT. Based on independent central $\left[{ }^{18} \mathrm{~F}\right]$ fluorodeoxyglucose (FDG) - positron emission tomography (PET) - computed tomography (CT) scan review, 42 of 52 evaluable patients (81\% [95\%CI: 67-90]) achieved an $\mathrm{mCR}$ before $\mathrm{HDC}$ /auto-PBSCT, five had an $\mathrm{mPR}$ and five had progressive disease ( 3 were not evaluable). After HDC/auto-PBSCT, four patients with an $\mathrm{mPR}$ converted to an mCR. Two-year PFS was 74\% [95\% CI: 63-86] and overall survival 95\% [95\%CI: 90-100]. Toxicity was manageable and mainly consisted of grade $3 / 4$ hematologic toxicity, fever, nephrotoxicity, ototoxicity (grade $1 / 2$ ), and transiently elevated liver enzymes during BV-DHAP. Eighteen patients developed new onset peripheral neuropathy (maximum grade 1/2); all recovered. In conclusion, BV-DHAP is a very effective salvage regimen in $\mathrm{R} / \mathrm{R}$ cHL patients, but patients should be monitored closely for toxicity. (clinicaltrials.gov identifier: NCT02280993).
Ferrata Storti Foundation

Haematologica 2021

Volume 106(4):1129-1137

\section{Correspondence:}

MARIE JOSÉ KERSTEN

m.j.kersten@amsterdamumc.nl

Received: November 18, 2019.

Accepted: March 19, 2020.

Pre-published: April 9, 2020.

https://doi.org/10.3324/haematol.2019.243238

(C)2021 Ferrata Storti Foundation

Material published in Haematologica is covered by copyright. All rights are reserved to the Ferrata Storti Foundation. Use of published material is allowed under the following terms and conditions:

https://creativecommons.org/licenses/by-nc/4.0/legalcode. Copies of published material are allowed for personal or internal use. Sharing published material for non-commercial purposes is subject to the following conditions:

https://creativecommons.org/licenses/by-nc/4.0/legalcode, sect. 3. Reproducing and sharing published material for commercial purposes is not allowed without permission in writing from the publisher. 